\title{
El poder de la música en el aprendizaje
}

\author{
Miguel Ángel Medina Martínez*
}

mmedinamartinez@yahoo.com.mx

Gilda Waisburd y Ernesto Edmenger

Trillas, 2007

Este libro puede resultar una interesante opción para los capacitadores, los líderes facilitadores de procesos y los maestros generadores de aprendizajes que buscan nuevas alternativas y herramientas para la educación en general a través de la música.

Aborda diversos tópicos acerca de la importancia cultural de la música y del papel que tiene a nivel individual no sólo para quien se dedica a ella o tiene talento musical sino para cualquier ser humano. No solamente como diversión y arte, sino como instrumento que aumenta la sensibilidad, la memoria, la concentración, las habilidades para la lectura y la escritura. Analiza los efectos de la música en los aspectos mentales, emocionales y físicos.

Explora también los elementos de lo que los autores llaman "el cerebro musical": la naturaleza del cerebro y sus conexiones nerviosas, las habilidades de los dos hemisferios y la posibilidad de favorecer la interconexión entre ambos con el propósito de desarrollar al cerebro completamente.

Se dice que la música de Mozart, por su simplicidad y pureza, misterio y accesibilidad tiene la habilidad para hacer que un ser humano exprese lo mejor de sí mismo. Al parecer, particularmente los conciertos de violín tienen un efecto curativo en el cuerpo humano. Según investigaciones recientes, la música mozarteana ha mostrado ser especialmente estimulante y revitalizante: a ella se le comienzan a atribuir poderes liberadores, curativos y sanadores, y por último, se establecen algunas relaciones entre la música y el aprendizaje acelerado.

En un libro como éste, no podía faltar un apartado relativo a la naturaleza de la creatividad, a las características de una persona, del proceso y del producto creativos, así como de los bloqueadores de la misma, en la persona y en la educación. Hace referencia también a los beneficios de la música en el desarrollo de la inteligencia emocional y en la creatividad. 
Capítulo esencial resulta el dedicado a la música como activadora de aprendizajes creativos y significativos, de desarrollo de la imaginación y de la fantasía, del lenguaje verbal y no verbal, de la apertura a nuevas experiencias, de hacer contacto con las emociones para aceptarlas y manejarlas, de encontrar soluciones a los problemas. En todo ello, se establecen las posibilidades de la música para fomentar una mente abierta, flexible y creadora, una voluntad para alcanzar otra visión con ideas nuevas, un corazón sensible, comprometido y empático, así como los

elementos necesarios para potenciar en el cuerpo los efectos de la música, para aprovechar el lenguaje musical de los niños y para contactar el niño interno que todos llevamos dentro.

Por último, más de la mitad del libro contiene una enorme cantidad de ejercicios para desarrollar la percepción auditiva, de gimnasia cerebral, de sensibilización, de calentamiento, de concentración, para armonizar, energetizar, para liberar emociones, de creación musical, para desarrollar la imaginación y la fantasía, para manejar el estrés, para desarrollar la creatividad musical, y de cierre e integración.

Asimismo, los autores ofrecen una serie de sugerencias discográficas cuyo objetivo es expandir la sensibilidad, activar el aprendizaje, la autoexploración y la imaginación. También, pretenden inducir con ello a la meditación, la reflexión, el goce, la relajación, la creatividad y despertar la intuición. La discografía incluye música clásica, new age, para meditación y relajación, de acompañamiento, bailable y de mensaje.

El libro finalmente, viene acompañado de un CD con muestras de varios estilos y autores en la historia de la música, que puede ser usado, además, como apoyo en la implementación de los ejercicios incluidos.

La naturaleza de un libro así, forja el anhelo de encontrarse con una articulación teórico práctica que permita sustentar el ejercicio de una educación integral, de un aprendizaje en el que se genere una praxis enriquecedora de la misma teoría. Me parece que al final de cuentas, se queda más en una aspiración apenas cumplida. Sin embargo, habrá que aplaudir la generación y la publicación de tales intentos hasta que finalmente se fragüen esos ejes que permitan reducir o desaparecer las escisiones en el pensamiento científico y dar cuenta más integralmente de las realidades humanas que nos atañen a todos, como lo es la educación. 